\title{
ReSENHAS
}

REVIEWS

\section{POR UMA GEOGRAFIA SEM CÁRCERES PÚBLICOS OU PRIVADOS}

\author{
Organização de Alcindo José de Sá \\ Universidade Federal de Pernambuco, Recife, 2007
}

Fernando Aith $^{(*)}$

Um dos aspectos mais instigantes que orienta os estudos sobre saúde pública e, conseqüentemente, sobre o Direito Sanitário, é certamente a sua natureza multidisciplinar. A compreensão deste campo do conhecimento humano exige um olhar abrangente que dê conta de sua complexidade.

A legislação brasileira de proteção do direito à saúde trata esta complexidade a partir do conceito de "fatores determinantes e condicionantes da saúde". De fato, a Lei Orgânica da Saúde, Lei n. 8.080 de 1990, dispõe em seu art. 3: "A saúde tem como fatores determinantes e condicionantes, entre outros, a alimentação, a moradia, o saneamento básico, o meio ambiente, o trabalho, a renda, a educação, o transporte, o lazer e o acesso aos bens e serviços essenciais; os níveis de saúde da população expressam a organização social e econômica do País." E complementa o parágrafo único: "Dizem respeito também à saúde as ações que, por força do disposto no artigo anterior, se destinam a garantir às pessoas e à coletividade condições de bem-estar físico, mental e social."

Desta forma, fatores relacionados ao ambiente em que uma pessoa vive são diretamente responsáveis pelas suas condições de saúde. Poluição do ar, poluição sonora, insalubridade, violência doméstica, violência urbana,

(*) Advogado, doutor em Direito Sanitário, professor de Redação e Estratégia Legislativa da Fundação Getúlio Vargas; pesquisador do Centro de Estudos e Pesquisas de Direito Sanitário CEPEDISA. E-mail: <feaith@uol.com.br>. 
dentre outros fatores, são condições ambientais que acabam determinando e condicionando a saúde da população.

A Constituição Federal orienta o Estado brasileiro a se organizar para a proteção da saúde, sendo que as ações específicas de segurança sanitária são exercidas majoritariamente pela vigilância em saúde, ou seja, por meio de ações de vigilância sanitária, ambiental, epidemiológica e de saúde do trabalhador que garantam o respeito às normas sanitárias existentes. Entram, neste campo de atuação da saúde pública, medidas de monitoramento e controle da violência na sociedade, especialmente quando geram demandas vultosas ao sistema público de saúde, como a violência urbana ou a violência do trânsito.

Dadas as complexidades que cercam o tema da saúde pública, a segurança sanitária também deve ser garantida por políticas multissetoriais que lidem com os diversos fatores determinantes da saúde, questões associadas à violência urbana e doméstica, ao saneamento básico, ao meio ambiente, às condições de habitação e transporte, entre outras.

O princípio da segurança sanitária exige do Direito Sanitário uma atualização permanente, especialmente em decorrência do constante aparecimento de riscos até então desconhecidos, ou do agravamento daqueles já conhecidos. Seja em conseqüência de uma grande crise (explosão de violência urbana, uma grande epidemia, transfusões de sangue contaminado, mortes ou danos por medicamentos falsos etc.), seja resultado de um futuro incerto (alimentos transgênicos, engenharia genética) o Direito precisa dar à sociedade uma resposta para temas fundamentais que a afligem e que podem representar grave risco social. Como bem diagnostica Durand, "se a legislação evolui graças às crises e se as crises permanecem inevitáveis, é inevitável também que o direito progrida e com ele a gestão dos riscos sanitários”(1).

É neste ponto que a publicação organizada pelo geógrafo Alcindo José de Sá, da Universidade Federal de Pernambuco - UFPE - traz elementos fundamentais que podem auxiliar os profissionais, que atuam na área da saúde, na compreensão das relações existentes entre a violência (sobretudo urbana) e a saúde da população.

O livro, publicado pelo Programa de Pós-Graduação em Geografia da UFPE, trata de questões relacionadas com a violência urbana que afetam diretamente as condições de saúde da população, trazendo temas derivados da violência como o medo, a loucura, as desigualdades na formação sócioespacial brasileira, a inutilização dos espaços públicos de lazer etc.

(1) DURAND. Christelle. A segurança Sanitária num mundo global: aspectos legais e o sistema de segurança sanitária na França. Revista de Direito Sanitário, São Paulo, v. 2, n. 1, p. 68. mar. 2001. 
A importância de agregar este tipo de conhecimento ao campo da saúde pública e aos estudiosos do Direito Sanitário fica ainda mais clara na medida em que nos deparamos com os últimos dados do "Mapa da Violência dos Municípios Brasileiros", divulgado recentemente no Brasil pela Rede de Informação Tecnológica Latino-Americana - Ritla - e pelos ministérios da Justiça e da Saúde. O "Mapa da Violência dos Municípios Brasileiros 2008" utiliza dados dos atestados de óbito cadastrados pelo Subsistema de Informação sobre Mortalidade do Ministério da Saúde. O estudo mostra que o Rio de Janeiro é a cidade onde mais morreram jovens em 2006: 879, de um total de 17.312 no país todo. A liderança, até 2005 , ficava com a cidade de São Paulo. Em 2006, 797 jovens foram assassinados na capital paulista.

O Mapa da Violência trouxe ainda dados que revelam como a violência está atrelada a outros fatores que induzem à piora das condições de saúde da população. De acordo com o Mapa, as cidades que mais desmatam no Brasil figuram também na lista das mais violentas do país. De acordo com matéria publicada pelo Jornal Folha de $S$. Paulo(2), de uma lista de 36 cidades responsáveis por metade da derrubada recente de árvores da Amazônia Legal, divulgada pelo Ministério do Meio Ambiente, 23 delas estão entre as $10 \%$ mais violentas do país.

O documento da Ritla apresenta uma relação com as 556 cidades mais violentas, que correspondem a $10 \%$ dos 5.564 municípios brasileiros e abrangem $44,1 \%$ da população do país e $73,3 \%$ dos homicídios ocorridos em 2006. Essas 556 cidades têm média de 144 mil habitantes - contra 32,6 mil nos demais municípios. Os dados de homicídios colocam na lista das $10 \%$ mais violentas 25 capitais do país (ficando fora Boa Vista/RR e Natal/ $\mathrm{RN})$ - municípios em região de fronteira, com conflitos de terra, turísticos e em desenvolvimento.

Organizada por Alcindo José de Sá, a obra apresenta um olhar novo sobre os reflexos da violência na organização espacial da sociedade, lançado a partir da perspectiva da geografia e das ciências sociais. Em vinte e quatro capítulos, o livro traz artigos de diversos autores unidos pela preocupação com a identificação de um fenômeno moderno, qual seja, o das transformações sociais decorrentes da violência urbana.

Destacam-se, assim, artigos que analisam a violência e suas conseqüências práticas para a vida das pessoas.

Logo no artigo de abertura, o organizador Alcindo José de Sá destaca o fato de que "tornou-se banal, em todos os veículos de comunicação no território brasileiro, a divulgação de manchetes que expressam crescente intolerância entre os seus indivíduos constituintes, ou seja, a ascensão de

(2) PINHO, Angela. Lista das cidades mais violentas inclui áreas de desmatamento. Folha de S. Paulo, São Paulo, 30. jan. 2008. Caderno/Cotidiano. 
uma anti-sociedade, de seres que não mais convivem em relativa harmonia". Daí em diante, o autor trata do impacto da violência urbana sobre a saúde pública: idosos mortos por adolescentes em sinais de trânsito; grupos de extermínio paramilitares contratados por valores que variam de $R \$ 500,00$ a $R$ \$ 2.000,00; violência de trânsito etc.

O trabalho seguinte, de Lúcia Leitão, analisa a construção dos espaços em uma sociedade socialmente desigual e marcada pelo medo da violência. Em sua conclusão, a autora, que atua na área do desenvolvimento urbano, expõe um interessante ponto de vista sobre a segregação social vista a partir do desenvolvimento urbano: "Erguemos edifícios altos, fechados contra rua, porque temos um profundo desprezo pela rua, o espaço público por excelência. Edificamos muros altos, com guaritas e cercas, não apenas para nos proteger de um ambiente hostil, mas porque somos uma sociedade segregadora como poucas. Fechamo-nos em condomínios e em shopping centers, em cárceres privados, não apenas por comodidade, ou porque nos sentimos inseguros em outros espaços, mas antes porque estes ambientes, de longe, anunciam a todos que são esses os espaços onde estão os senhores que não se querem confundir com o povo."

Este artigo dialoga de forma bastante rica com o texto dos geógrafos Antonio Albuquerque da Costa e Alcindo José de Sá, denominado "Metamorfoses dos Espaços Públicos: o Medo que Transforma as Praças em Percursos Tangenciáveis". Analisando a evolução dos espaços públicos no Município de Campina Grande, na Paraíba, os autores chegam à seguinte conclusão: 'Uma 'quase institucionalização' da violência e do medo fez com que ruas, praças e parques de nossa cidade se transformassem em espaços cuja utilização segura é limitada a certos horários do dia, pois, na maior parte do tempo, alguns desses espaços são tangenciáveis, cuja permanência é 'comprometedora' ou de risco para os possíveis freqüentadores. Como os lugares respondem distintamente a certos fenômenos, percebemos que a resposta de algumas camadas da população campinense foi o enclausuramento, o que resultou em espaços públicos mais inseguros, porque vazios, ou ocupados por "delinqüentes."

Muitos outros trabalhos desta obra poderiam ser objeto de atenção mais detalhada nesta resenha, dado o conteúdo extremamente rico dos mesmos. A publicação conta com artigos como: "Prisão e Loucura: uma geografia de Intensidades", de Ana Maria Prevê; "Territórios de Pouca Fé: Uma Análise dos Testemunhos de Insegurança e Medo na cidade Contemporânea a partir de Juazeiro do Norte/CE, de Ivan da Silva Queiroz; "A Prisão, as Desigualdades e a formação Sócio Espacial Brasileira", de James Humberto Zomighani Junior, "Cidade Média com Problema de Cidade Grande? A Percepção de Insegurança em Garanhuns/PE”, de Luiz Eugênio Pereira Carvalho e outros; dentre outros. 
Para finalizar, vale destacar o artigo "Miedo y Exclusion Social en la Ciudad: La Juventud Desplazada por el Conflicto Armado en Colombia", escrito pelos pesquisadores colombianos Gloria Evelyn Martinez e Jacinto Pineda Jiméne e que traz, com requintes de detalhes, as conseqüências à saúde das pessoas geradas por uma situação de violência, como a vivida pelos colombianos.

O olhar multidisciplinar sobre a saúde pública é um imperativo. No campo do Direito Sanitário, conhecer as conexões existentes entre os fatores determinantes e condicionantes da saúde e as regras de organização jurídica da sociedade é fundamental. As informações trazidas no livro "Por Uma Geografia Sem Cárceres Públicos ou Privados" são extremamente ricas para que possamos compreender, com maior detalhamento, o emaranhado de problemas sanitários causados pela violência. A leitura do livro nos permite verificar que, além de ser uma das grandes responsáveis pelas internações em hospitais públicos, a violência também gera outros vários problemas de saúde pública, como o medo coletivo e a sensação de insegurança, a desistência das pessoas de usar os espaços públicos, o enclausuramento social das classes mais privilegiadas, a morte prematura de jovens. Estes são problemas que deixam explícitas as dificuldades de se viver em um ambiente violento e com suas conseqüências para a saúde humana. Tanto pela originalidade do tema, como pela abordagem extremamente rica e inovadora, o livro vale a leitura.

\section{REFERÊNCIAS BIBLIOGRÁFICAS}

DURAND. Christelle. A segurança Sanitária num mundo global: aspectos legais e o sistema de segurança sanitária na França. Revista de Direito Sanitário, São Paulo, v. 2, n. 1, p. 68. mar. 2001.

$\mathrm{PINHO}$, Angela. Lista das cidades mais violentas inclui áreas de desmatamento. Folha de S. Paulo, São Paulo, 30. jan. 2008. Caderno/Cotidiano. 